\title{
Time to reimbursement and negotiation condition in Italy for drugs approved by the European Medicines Agency during the period 2014-2019
}

\author{
Mariangela Prada, Letizia Rossi, Matteo Mantovani \\ Intexo Società Benefit, Rome - Italy
}

\begin{abstract}
Introduction: The main purpose of this study was comparing median time (TTR, time to reimbursement) between the first Agenzia Italiana del Farmaco (AIFA) pricing and reimbursement (P\&R) dossier's evaluation and patient access in Italy and to observe the key P\&R negotiation results for all new active substances approved by the European Medicines Agency (EMA)'s Committee for Medicinal Products for Human Use between January 2014 and December 2019. We analysed the different factors influencing TTR.

Methods: A panel of medicines for human use approved by the EMA in the period 2014-2019 was considered. All information about authorisation and reimbursement in Italy, including timelines and results from the negotiation, were gathered through EMA and Italian Official Journal databases.

Results: Of 213 new active substances approved from January 2014 to December 2019, 137 obtained reimbursement in Italy, with a median TTR of 7.6 months (228 days). Even if orphan designation, oncology indication, application of Managed Entry Agreements (MEAs; both outcome and financial based) or a discount did not show an impact on TTR, recognition of full innovativeness ( $n=27 ; 20 \%)$ was associated with a reduction of 1 month in median TTR. Interestingly, drugs reimbursed with a lower price/daily defined dose showed a reduced TTR (-22\%). Conclusions: Even if the lack of impact of some negotiation conditions was predictable (e.g. oncology indication or orphan status) or the application of a MEA helped to manage possible uncertainties, it did not lead to a quicker completion of the negotiation procedure. Likewise, full innovative drugs showed a shorter TTR underlying the AIFA commitment in recognising, promoting and rewarding innovation.
\end{abstract}

Keywords: Accessibility, Market Access, Regulatory, Reimbursability, Time to market

\section{Introduction}

In order to be marketed and sold, a medicinal product needs to have a marketing authorisation (MA). In Europe, medicinal products can obtain a MA valid in all European Union (EU) member states, as well as in the European Economic Area (EEA) countries, Iceland, Norway and Liechtenstein, through the so-called 'centralised procedure' (CP), which is set out in Regulation (European Commission [EC]) 726/2004 (1). This particular procedure is the most widely used and is

Received: September 15, 2020

Accepted: November 24, 2020

Published online: December 18, 2020

Corresponding author

Mariangela Prada

Patient Access Director

Intexo Società Benefit

Via del Tritone, 169 - 00187 Rome - Italy

mariangela.prada@intexo.it compulsory for all the medicinal products for human use derived from biotechnology and other high-technology processes (2). The European Medicines Agency (EMA) is responsible for the scientific evaluation of applications for centralised MA in the EU. Medicines are evaluated by the EMA's Committee for Medicinal Products for Human Use (CHMP), composed of members from all EU/EEA states, which performs a scientific assessment, providing an opinion on granting the MA. EMA sends this opinion to the EC, who takes a legally binding decision based on EMA's recommendation, within 67 days of receipt of CHMP opinion (3). EC decisions are published in the Community Register of medicinal products for human use and, within 60 days, in the Official Journal of the European Union (OJEU). Even if the MA obtained through CP is valid in all EU/EAA member states, new medicines are not immediately available for patients in all EU countries.

Once authorised by the EMA, Italy, as a member state of the European Community, automatically accepts drug MA by defining, throughout the Italian Regulatory Authority (Agenzia Italiana del Farmaco - AIFA), the supply regimen and by assigning a national MA code. All these drugs are automatically placed into a specific class, for drugs not evaluated for 
the reimbursement by National Healthcare System (NHS). This new class is named C ( $\mathrm{nn}$ ) class, where $\mathrm{C}$ stands for 'not reimbursed' and ' $n n$ ' stands for 'not negotiated'. The resolution concerning the MA and the classification is published in the Italian Official Journal (IOJ) within 60 days after the publication of the EC decision in the OJEU, and the medicine can be commercialised (4). This allows new medicines to be potentially quickly available for patients.

The process to obtain the reimbursement of a medicinal product starts with the official request for reclassification and pricing definition, submitted to AIFA by the pharmaceutical company, through a pricing and reimbursement (P\&R) dossier. The request can be submitted after the publication of the EC decision in the Community Register of medicinal products for human use. For orphan drugs (ODs) and/or drugs with exceptional therapeutic relevance and/or drugs that can be used only in hospital settings, the request of classification and pricing can be submitted to AIFA immediately after the CHMP positive opinion. Under the Act 98/2013, AIFA has been assigned the task of prioritising ODs and drugs of exceptional therapeutic relevance, with a maximum 100-day evaluation time (so-called fast-track authorisation) (5). After an administrative check and a preliminary assessment conducted by the AIFA's P\&R Secretariat of the AIFA Health Technology Assessment (HTA) and Pharmaceutical Economic Division (Settore HTA ed Economia del Farmaco), the P\&R dossiers are evaluated by the Technical Scientific Commission (CTS) and by the Prices and Reimbursement Committee (CPR). The process is carried out according to transparent methods, timelines and procedures, as established by Law n. 326 of 24 November 2003 and the Interministerial Committee for Economic Planning (Comitato Interministeriale per la Programmazione Economia CIPE) Resolution of 1 February 2001.

The CTS evaluates medicinal products from a clinical point of view, making a binding opinion on the therapeutic value of the medicinal product. In particular, it establishes whether a medicinal product can be reimbursed or not by the NHS and the class of reimbursement (class $A$ or $\mathrm{H}$, essential products or drugs for chronic disease are totally reimbursed by the NHS). Products not reimbursed by the NHS are included in class C. Pharmaceutical companies establish class $C$ pharmaceutical prices, which are then communicated to AIFA without any publication in the Official Journal. Increases in the price of class $\mathrm{C}$ medicines are allowed only in the month of January of odd-numbered years (6). The CTS also establishes the place in therapy, identifies the comparators and evaluates, when applicable, if a product is 'innovative'. The score of therapeutic innovation is assessed according to three AIFA criteria. 1) Unmet Therapeutic Need evaluation determines the availability of other therapies; the drug is graded on the basis of five levels, from maximum (no therapeutic alternative) to absent. 2) Therapeutic Added Value evaluation determines the clinical benefit provided by the new drug compared to available alternatives. This value can be from maximum (greater clinical benefit than alternatives) to absent. 3) Quality of Evidence: AIFA uses the GRADE method (Grading of Recommendations Assessment, Development and Evaluation) to determine evidence quality, which ranges from very low to high. The quality of evidence for ODs will have a smaller impact, because of the difficulty of conducting trials for rare diseases (7). Based on this score, medicines can receive either a full or a conditional innovation status. When a drug is recognised as fully innovative, it has access to economic incentives for 36 months and is not subject to the refund mechanism (Act 222/2007, Article 5). It has also access to a special fund consisting of resources deriving from budget savings (8). Under the Stato-Regioni Agreement, signed on 18 November 2010, enhanced by the Balduzzi Decree (Article 10, comma 2, Act 189/2012), patient access to innovative medicines must be guaranteed immediately after approval across all Italian regions. When a drug is recognised as conditionally innovative, it does not have access to economic benefits, but the immediate availability of the medical products across the Italian region is granted (9).

After the CTS evaluation, the CPR carries out the activity of negotiation with pharmaceutical companies for setting the prices of medicinal products reimbursed by the NHS. The CPR examines the proposals taking into account the assessments made by the CTS with particular reference to the positive cost/benefit ratio and the added value of the new chemical entity. Other criteria considered are the place in therapy of the new product, the treatment cost/day ratio according to the National Health Service compared to other products with same efficacy already available, an estimation of the potential market share acquirable in the next 36 months in the specific market segment and a comparison with the prices and consumption data of other European countries (10). To enable access to health technology subject to certain conditions, AIFA often relies on discount (often 'hidden') and on Managed Entry Agreements (MEAs) (11). MEAs have been introduced to manage the uncertainty when patients' eligibility criteria to treatments are complex and when there is a higher uncertainty on drug's effects in real life (12). These agreements can be divided into two groups: financial based and outcome based. In the first group, both agreements, at the population level (e.g. cost sharing [CS] or price volume [PV]) and at the patient level (e.g. cost capping per patient), allow payers to share with the industry the post-marketing budget impact of new drugs. Outcome-based agreements link payers' commitment to the actual clinical value of the drugs on health. This second category includes payment by result (PbR), risk sharing, success fee and a new agreement, first and only used in 2019, named 'payment at result' (PaR). The management of MEAs is controlled by AIFA through the use of specific monitoring registries. The Registry tracks the eligibility of patients, guarantees the appropriate use of medicines according to their approved indications and evaluates the effectiveness of treatment and its safety profile in clinical practice (13).

After the CPR evaluation, if an agreement is reached, the results of the negotiation are submitted to the AIFA's Board of Directors (BoDs) for a final evaluation.

The CTS and CPR express their decisions within 180 days from the application, and it is published in the Official Journal (Gazzetta Ufficiale). In addition, the AIFA approval time for ODs is above the 100-day timespan fixed by the introduced Act 98/2013 for the approval of orphan and innovative drugs in the Italian NHS. 
Once the national evaluation is completed, a new drug is usually not immediately available in every hospital or pharmacy, except for innovative drugs, which receive immediate access to regional formularies. Otherwise, the drug's approval process needs to undergo further steps that are different from one region to another. Even within a single region these steps may vary among the different health districts and hospitals. The regional drug access is a fragmented and complex process; both the timing and the number of drugs available for patients are widely different from region to region. Due to these different procedures and to regional decision-making autonomy, discrepancies and inequalities between different regions in the timing of patient access are created.

\section{Methods}

The main purpose of this analysis was to compare the median time between the fist AIFA (CTS) P\&R evaluation and patient access, measured by the number of days elapsing from the date of first dossier's evaluation by CTS to the day of the final assessment of the AIFA's BoDs (= time to reimbursement; TTR), and to observe the key $P \& R$ negotiation results (prices and agreed conditions) for all the new active substances approved by the EMA's CHMP between January 2014 and December 2019.

\section{Panel selection}

The evaluated panel of products has been defined according to the chronological criterion of EMA's centralised licensing procedure. In particular, this analysis includes all new drugs which received a positive CHMP opinion between January 2014 and December 2019, followed by the EC approval. Our panel includes only the first application of new active substances, excluding generics, known active substances and all possible further extensions of therapeutic indications or other different procedures (new pack sizes, new formulations).

\section{Data source}

Data gathering relied on the World Health Organization (WHO) website, the EMA website, the AIFA website, the official administrative acts of MA published on both the Italian and European Official Journal, the reports of the AIFA committee meetings and the public purchases of drugs.

\section{Data collected}

For each medicinal product included in the panel, basic information was collected, such as therapeutic indications and dates of CHMP positive opinion and EC decision. In addition, the conditions of the evaluation at the European level were included: advanced therapy medicinal products (ATMP) and PRIority MEdicines (PRIME) designation, orphan designation at the time of the approval, conditional MA and approval under exceptional circumstances. After that, the TTR was estimated as the time between the first dossier's evaluation by the CTS and the day of the final assessment of the AIFA's BoDs concerning the price and reimbursement condition (excluding renegotiation), expressed in days. Then, we collected all the negotiation conditions (class of reimbursement, MEAs, capping, discounts). With regard to pricing, for each single drug, we considered the price per DDD (daily defined dose) (14), calculated starting from the ex-manufacturer price, published into the IOJ and we considered the price applied on the public purchases, when available, in order to identify the hidden discount (HD) negotiated.

\section{Results}

Between January 2014 and December 2019, 498 medicinal products were recommended for authorisation by the CHMP and approved by the EC, and 213 of them were new active substances (NAS) (Fig. 1).

Out of the 213 NAS, 65 (30\%) were ODs at the time of the approval, $10(5 \%)$ were ATMP, and $5(2 \%)$ received the PRIME designation. Twenty-seven (13\%) MA procedures were evaluated through an accelerated assessment, 6 (3\%) were approved under exceptional circumstances and 24 (11\%) were approved with conditional MA; among the last mentioned, $6(25 \%)$ were switched to normal MA in the following years. Among all considered medicinal products, in nine cases the MA application was withdrawn.

In May 2020, reimbursement was granted to 137 (64\%) medicinal products. Out of the 76 which were not reimbursed, the majority (65\%) received a positive recommendation by the CHMP in 2018 and 2019, so we can suppose that no agreement has been yet reached. A total of 16 of the 76 NAS not reimbursed $(21 \%)$ were included in class $C$ and $60(79 \%)$ were still in the negotiating phase (in 23/60 [38\%] there are evidences of ongoing procedures).

Our analysis highlighted that in the past 6 years, the TTR of NAS reimbursed in Italy does not follow a linear trend (Fig. 2), with a median TTR of 7.6 months (228 days, range 12-870). For NASs which received a CHMP positive opinion in 2014 $(n=33)$ and $2015(n=31)$, the median TTR was, respectively, 4.7 and 6.7 months (142 and 201 days, average 263 and 219 days, range 20-799 and 34-568). For drugs approved in 2016

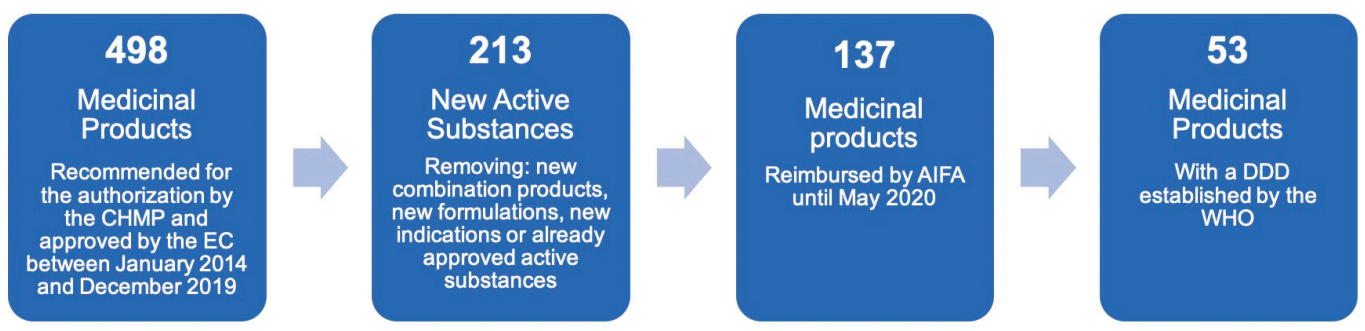

Fig. 1 - Method for product selection. AIFA = Agenzia Italiana del Farmaco; CHMP = Committee for Medicinal Products for Human Use; DDD = daily defined dose; $E C=$ European Commission; $\mathrm{WHO}=$ World Health Organization. 


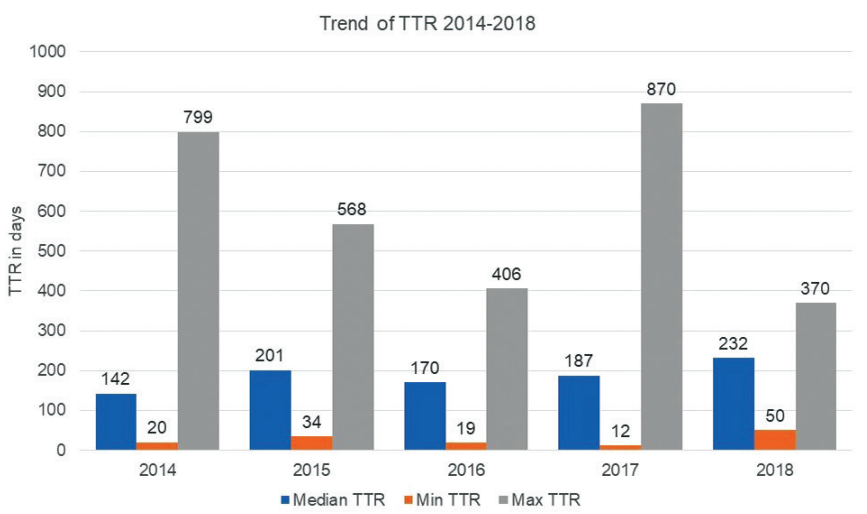

Fig. 2 - Trend of time to reimbursement (TTR) 2014-2018.

( $n=25$ ) and $2017(n=25)$, we observed an initial reduction in TTR (almost 5.7 and 6.2 months: 170 days, average 184 days, range 19-406 and 187 days, average 236 days, range 12-870), with an increase for 2018 approved NASs ( $n=22)$ (7.7 months: 232 days, average 236 days, range 50-370). Only one of the drugs approved in 2019 (3\%) is currently reimbursed; therefore, it is impossible to assess the TTR's trend.

Table I shows the different negotiation conditions which affected the median TTR: the orphan designation at the time of the MA (TTR for ODs and non-ODs is quite similar: median 206 days, average 257 days, range 19-870 vs. median 191 days, average 213 days, range 12-693), oncology indication

TABLE I - Negotiation conditions which affected the TTR

\begin{tabular}{|c|c|c|c|c|c|c|}
\hline & $\begin{array}{l}\text { Drugs } \\
\text { (N.) }\end{array}$ & $\begin{array}{c}\text { Median } \\
\text { TTR } \\
\text { (days) }\end{array}$ & SD & $\begin{array}{c}\text { Min } \\
\text { TTR } \\
\text { (days) }\end{array}$ & $\begin{array}{c}\text { Max } \\
\text { TTR } \\
\text { (days) }\end{array}$ & $\begin{array}{c}\text { Mean } \\
\text { TTR } \\
\text { (days) }\end{array}$ \\
\hline \multicolumn{7}{|c|}{ Orphan drug status } \\
\hline No & 91 & 191 & 130 & 12 & 693 & 213 \\
\hline Yes & 46 & 206 & 196 & 19 & 870 & 257 \\
\hline \multicolumn{7}{|c|}{ Oncology drug } \\
\hline No & 94 & 170 & 157 & 12 & 870 & 214 \\
\hline Yes & 43 & 232 & 151 & 50 & 799 & 259 \\
\hline \multicolumn{7}{|c|}{ Innovation status } \\
\hline No & 96 & 194 & 160 & 20 & 799 & 237 \\
\hline Yes & 41 & 190 & 147 & 12 & 870 & 208 \\
\hline Full & 27 & 162 & 169 & 12 & 870 & 197 \\
\hline Conditional & 14 & 218 & 93 & 57 & 379 & 229 \\
\hline \multicolumn{7}{|l|}{ MEAs } \\
\hline No & 97 & 188 & 138 & 20 & 742 & 216 \\
\hline Yes & 40 & 203 & 193 & 12 & 870 & 256 \\
\hline \multicolumn{7}{|l|}{ Discount } \\
\hline No & 24 & 197 & 204 & 19 & 799 & 248 \\
\hline Yes & 113 & 192 & 145 & 12 & 870 & 224 \\
\hline
\end{tabular}

MEA = Managed Entry Agreement; Drugs (N.) = number of drugs with MEAs analysed; $\mathrm{SD}=$ standard deviation; TTR = time to reimbursement.
( $n=43$ [31\%] NAS; compared to non-oncology drugs [ $n=94$; $69 \%$ ], the TTR is 2 months longer [median 232, average 259 days, range 50-799 vs. median 170 days, average 214 days, range 12-870]). Recognition of innovativeness ( $n=41 ; 30 \%$ ) was not associated with a reduction in median TTR. On average, the median TTR of these drugs was only few days shorter (190 days, average 208 days, range 12-870) than TTR for non-innovative drugs (194 days, average 237 days, range 20-799). Out of the 41 innovative drugs, 27 (66\%) received the full innovation status and the median TTR was 1 month shorter than non-innovative drugs, 6.5 vs. 5.4 months (162 days, average 197 days, range 12-870); the remaining 14 (34\%) received a conditional innovation status, and their median TTR was almost 7.3 months (218, average 229 days, range 57-379).

Out of the 137 medical products currently reimbursed in Italy, 113 NAS (83\%) were negotiated through a discount, and $40(29 \%)$ were negotiated through a MEA, with a median TTR of 6.4 and 6.8 months (192 and 203 days, range 12-870 and 12-870), respectively.

Financial agreements (79\%), mainly ceiling caps and PV, are the preferred approach to make NAS sustainable. Nevertheless, the application of these agreements granted a quicker median TTR (158 and 196 days, respectively), as shown in Table II.

Our data clearly show how in the past 5 years, ahead of an increase in the application of HD (in 2017 and 2018 only one NAS [out of 47] was negotiated without a discount), there was a strong decrease in the application of MEAs (Fig. 3).

Regarding the relation between price/DDD and TTR, we analysed data on 53/137 (38\%) NAS, excluding from the analysis drugs for which no DDDs have been established by the WHO, because of highly individualised use and wide dosage ranges. To assess the impact of the price/DDD on the TTR, we split our panel into two clusters: a) drugs with a price/DDD $<100$ Euro $(n=36)$ and b) drugs with a price/DDD $>100$ Euro ( $n=17$ ). Interestingly, drugs from cluster a) showed a shorter median TTR than drugs from cluster b) $(-22 \%, 196$ [range 20-693] vs. 252 days [range 74-870]). Just 1 (/36) drug from cluster a) vs. $59 \%$ from cluster b) had an orphan status and 1 (/36) drug on cluster a) was innovative (vs. $35 \%$ on cluster b)

TABLE II - Application and TTR of performance-based risk sharing vs. financial agreements

\begin{tabular}{lcccccccc}
\hline & \multicolumn{3}{c}{$\begin{array}{c}\text { Performance-based } \\
\text { risk-sharing agreements }\end{array}$} & \multicolumn{3}{c}{$\begin{array}{c}\text { Financial-based } \\
\text { agreement }\end{array}$} \\
\hline & PaR & $P b R$ & $\begin{array}{c}\text { Confidential } \\
\text { agreements }\end{array}$ & $\begin{array}{c}\text { CS } \\
\text { Cost }\end{array}$ & $\begin{array}{c}\text { Cap } \\
\text { flat }\end{array}$ & PV \\
\hline Drugs (N.) & 2 & 5 & 2 & 7 & 1 & 12 & 13 \\
Median TTR (days) & 289 & 225 & 212 & 258 & 253 & 158 & 196 \\
Min TTR (days) & 245 & 19 & 102 & 137 & 253 & 12 & 12 \\
Max TTR (days) & 332 & 577 & 321 & 799 & 253 & 870 & 612 \\
Mean TTR (days) & 289 & 261 & 212 & 322 & 253 & 224 & 209 \\
\hline
\end{tabular}

$\mathrm{CS}=$ cost sharing; $\mathrm{PaR}=$ payment at results; $\mathrm{PbR}=$ payment by results; $\mathrm{PV}=$ price volume; $\mathrm{TTR}=$ time to reimbursement. 


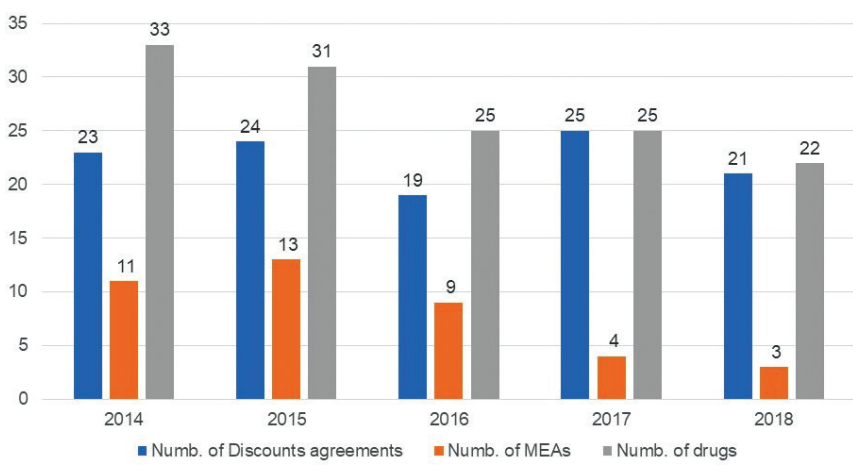

Fig. 3 - Annual trend in application of hidden discounts (HDs) and Managed Entry Agreements (MEAs).

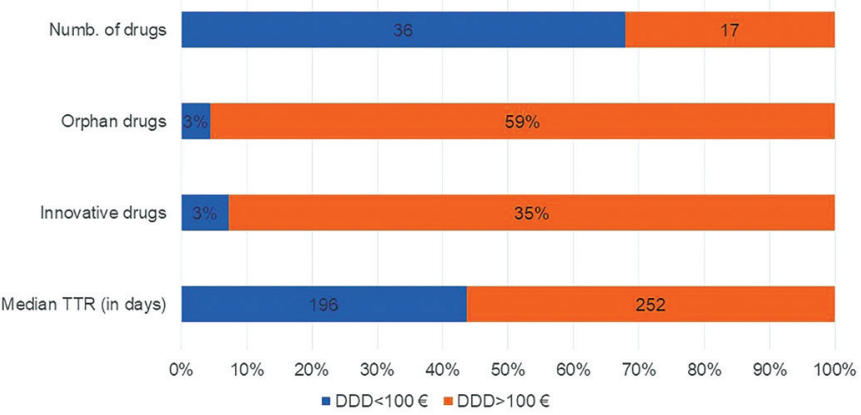

Fig. 4 - Relation between price/daily defined dose (DDD) and time to reimbursement (TTR).

(Fig. 4). Out of 53 drugs with DDDs, 43 (81\%) were negotiated through a discount. We analysed the difference between the ex-factory price published on the IOJ and the price applied on the public purchases, when available, in order to identify the HD negotiated. For two drugs it was not possible to find a public tender price and three drugs resulted as not marketed in Italy. Our data show that the average HD is higher for drugs with an official price/DDD $>100$ Euro (36.2\%, range $15.0 \%$ $56.7 \%)$ than for drugs with a price/DDD $<100$ Euro (31.6\%, range $9.7 \%-57.7 \%$ ).

The average HD for all new reimbursed drugs (with a DDD; 43 ) is $33.4 \%$ (30.8\% and $34.1 \%$ for ODs and non-ODs, respectively; $33.2 \%$ and $33.6 \%$ for innovative and non-innovative drugs, respectively, and $34.1 \%$ for non-innovative drugs and non-ODs).

\section{Conclusions}

This analysis allows us to observe trends and dynamics in the access to NAS in Italy in a consistent timeframe, trying to examine which factor most affects the TTR. Even if our results do not show a clear trend in reduction or increase of TTR, they show that only the full innovation status granted by the AIFA CTS allows drugs to be made available in a shorter time than non-innovative drugs (no differences between non-innovative and 'conditional' innovation status in TTR).
This reduction in TTR underlies the AIFA commitment in recognising, promoting and rewarding innovation.

By contrast, the adoption of an MEA, although it may help to manage possible uncertainties, does not lead to a quicker completion of the negotiation procedure and in the last months, HDs seem to be preferred to these more sophisticated regulatory tools. This may depend on the complexity of their management, which involves a network of 3,500 Italian hospitals, 52 regional managers, 963 health directors, 32,857 doctors and 2,318 pharmacists (13).

Unexpectedly, the drug's orphan status does not seem to have an impact on the TTR, even if the Italian regulation allows the P\&R dossier to be submitted immediately after the CHMP positive opinion (instead of waiting for the EC decision, as for the non-ODs). This may be explained by the long negotiation process required for the reimbursement of ODs, due to the potential absence of hard final endpoints and high prices proposed by pharmaceutical companies. Likewise, oncology drugs do not show a quicker TTR compared to non-oncology drugs, but actually the TTR for oncology drugs is 2 months longer. It would be interesting to analyse their clinical data in order to assess their therapeutic added value compared to the standard of care at the time of their launch in terms of survival (improved rate or prolongation of survival) to determine whether this had an impact on the TTR (15).

Interestingly, drugs with a lower price/DDD showed a reduced TTR vs. drugs with a higher price/DDD (-22\%). This could highlight the AIFA's accurate commitment to evaluating important drugs for Italian patients. Considering that the majority of the drugs with a price/DDD higher than 100 Euros (59\%) were orphan (and therefore with an implicit unmet medical need) and $35 \%$ have been recognised by the AIFA CTS as innovative (vs. 1/36 on the other cluster), our data could also suggest the engagement of AIFA in starting the implementation of a valuebased pricing system (16). The analysis shows that the HD percentage negotiated is higher for drugs with high cost/DDD and for neither innovative nor ODs. These data are consistent with data recently published by Villa et al. (12), which showed lower HD for ODs. By our analysis, innovative drugs seem not to have an average higher HD than the other molecules. This difference may be influenced by different timeframes and type of drugs included in our analysis (e.g. NAS with no DDDs established by the WHO were excluded). Further studies are needed to better investigate this specific topic.

Our analysis has some limitations. As an example, not all the information is public and available. When we consider the TTR, we do not have any details about the time of the dossier submission by the Marketing Authorization Holder (MAH) (which may lead to a longer TTR, not attributable to the negotiation).

Despite the limitation, our analysis completes and reinforces the currently available data on TTR for drugs in Italy, which are limited to oncology drugs (17-19) or exclusively focused on TTR, without considering the impact of the different negotiation conditions on it (20).

To our knowledge, this is the first analysis able to provide information about drug prices and TTR (higher price - higher TTR). The low TTR for full innovative drugs shows the strong commitment of our Italian Agency in providing innovative 
drugs an advantage in terms of approval times in order to offer Italian patients quick access to these important drugs.

\section{Disclosures}

Conflict of interest: The authors declare no conflict of interest. Financial support: This research received no specific grant from any funding agency in the public, commercial or not-for-profit sectors.

\section{References}

1. EUR-Lex. Regulation (EC) No $726 / 2004$ of the European Parliament and of the Council of 31 March 2004 laying down Community procedures for the authorisation and supervision of medicinal products for human and veterinary use and establishing a European Medicines Agency. Online Accessed July 8, 2020.

2. EUR-Lex. Council Regulation (EEC) No 2309/93 of 22 July 1993 laying down Community procedures for the authorization and supervision of medicinal products for human and veterinary use and establishing a European Agency for the Evaluation of Medicinal Products. Online Accessed July 8, 2020.

3. European Medicines Agency. Obtaining an EU marketing authorisation, step-by-step. Online Accessed July 8, 2020.

4. AIFA. Comunicato alle aziende farmaceutiche relativo agli adempimenti successivi all'entrata in vigore della legge 8 novembre 2012 n. 189, di conversione del decreto legge $n$. 158/2012 recante 'disposizioni urgenti per promuovere lo sviluppo del paese mediante un piu' alto livello di tutela della salute'. Online Accessed July 8, 2020.

5. Gazzetta Ufficiale. LEGGE 8 novembre 2012, n. 189. Online Accessed July 8, 2020.

6. Gazzetta Ufficiale. DECRETO-LEGGE 27 maggio 2005, n. 87. Online Accessed July 8, 2020.

7. AIFA. Criteri di valutazione dell'innovatività. Online Accessed July 8, 2020.

8. Gazzetta Ufficiale. Art. 9. Proroghe e disposizioni in materia di farmaci. Online Accessed July 8, 2020.

9. Gazzetta Ufficiale. Art. 10. Modificazioni al decreto legislativo 24 aprile 2006, n. 219, e norme sull'innovatività terapeutica. Online Accessed July 8, 2020.
10. Gazzetta Ufficiale. DECRETO 2 agosto 2019, n. 185. Online Accessed July 27, 2020.

11. Villa F, Jommi C, Genazzani A, Antignani S, Montilla S, Melazzini M. Accesso precoce al mercato: dalle approvazioni condizionate di EMA agli accordi negoziali particolari di AIFA. Glob Reg Health Technol Assess. 2018(5);1. CrossRef

12. Villa F, Tutone M, Altamura G, Antignani S. Determinants of price negotiations for new drugs. The experience of the Italian Medicines Agency. Health Policy. 2019;123(6):595-600. CrossRef Medline

13. AIFA. Registri farmaci sottoposti a monitoraggio. Online Accessed July 8, 2020.

14. WHO. ATC/DDD Index 2020. Online Accessed July 8, 2020.

15. Trotta F, Mayer F, Barone-Adesi F, et al. Anticancer drug prices and clinical outcomes: a cross-sectional study in Italy. BMJ Open. 2019;9(12):e033728. CrossRef Medline

16. Jommi C, Armeni P, Costa F, Bertolani A, Otto M. Implementation of value-based pricing for medicines. Clin Ther. 2020;42(1): 15-24. CrossRef Medline

17. Russo P, Mennini FS, Siviero PD, Rasi G. Time to market and patient access to new oncology products in Italy: a multistep pathway from European context to regional health care providers. Ann Oncol. 2010;21(10):2081-2087. CrossRef Medline

18. Gori S, Di Maio M, Pinto C, et al.; AIOM Working Group 'Interactions with Regional Sections' (2009-2011). Disparity in the 'time to patient access' to new anti-cancer drugs in Italian regions. Results of a survey conducted by the Italian Society of Medical Oncology (AIOM). Tumori. 2011;97(4):442-448. CrossRef Medline

19. Prada M, Ruggeri M, Sansone C, De Fazio D, Tettamanti A Mantovani M. Timeline of authorization and reimbursement for oncology drugs in Italy in the last 3 years. Medicine Access@ Point Care. 2017;1(1): e29-e36. CrossRef

20. Lidonnici $\mathrm{D}$, Ronco $\mathrm{V}$, Isernia $\mathrm{M}$, et al. Tempi di accesso ai farmaci in Italia nel periodo 2015-2017: Analisi delle tempistiche di valutazione dell'Agenzia Italiana del Farmaco. Glob Reg Health Technol Assess. 2018;1(5). CrossRef 